\title{
Protein of Vascular Endothelial Growth Inhibitor 174 Inhibits Epithelial-Mesenchymal Transition in Renal Cell Carcinoma In Vivo
}

\author{
QIANG ZHAO ${ }^{1 *}$, XIAOHU DENG ${ }^{2 *}$, BAOAN HONG $^{3 *}$, FENG WANG $^{4}$, XINXIN TANG $^{1}$, \\ YONG YANG ${ }^{1}, \mathrm{KAN} \mathrm{GONG}^{3}$, LIN YE $^{5}$, WEN G. JIANG ${ }^{5}$ and NING ZHANG ${ }^{1}$ \\ ${ }^{1}$ Beijing Institute for Cancer Research, Department of Urology, Beijing Cancer Hospital, Beijing, P.R. China; \\ ${ }^{2}$ Department of Urology, Karamay People's Hospital, Xinjiang, P.R. China; \\ ${ }^{3}$ Department of Urology, Peking University First Hospital, Institute of Urology, \\ Peking University, Beijing, P.R. China; \\ ${ }^{4}$ Department of Urology, First Affiliated Hospital of Xinjiang Medical University, Xinjiang, P.R. China; \\ ${ }^{5}$ Cardiff China Medical Research Collaborative, Cardiff University School of Medicine, Cardiff, U.K.
}

\begin{abstract}
Background: Vascular endothelial growth inhibitor (VEGI) is a member of the tumor necrosis factor superfamily, identified as an anti-angiogenic cytokine. However, the effect of VEGI on epithelial-mesenchymal transition (EMT) in renal cell carcinoma (RCC) is still unknown. Materials and Methods: In this study, protein VEGII74 was designed and synthesized. Renal cell carcinoma A498 cells were implanted into immune-deficient mice to establish tumor models. Two groups were included: control group treated with saline, and VEGI174-treated group. Data of tumor growth were collected every 3 to 4 days. Two weeks later, the tumor specimens were harvested for immunohistochemical staining of EMT markers (E-cadherin, $N$-cadherin, vimentin). Results: Compared to the saline-treated group, the VEGI174-treated group showed significant inhibition of tumor growth $(p<0.05)$. The expression of E-cadherin was significantly higher in the $V E G I 174-t r e a t e d$ group compared to the saline-treated group $(p<0.01)$. However, the expression of $N$-cadherin and vimentin were reduced in the VEGI174-treated group. Conclusion: Our findings indicate that VEGII74 prevents progression and
\end{abstract}

*These Authors contributed equally to this study.

Correspondence to: Professor Wen G. Jiang, Cardiff China Medical Research Collaborative, Cardiff University School of Medicine, Heath Park, Cardiff, CF14 4XN, U.K. Tel: +44 2920687065, e-mail: jiangw@cf.ac.uk and Professor Ning Zhang, Beijing Institute for Cancer Research, Beijing Cancer Hospital, 52 Fucheng Road, Haidian District, Beijing, 100142, P.R. China. Tel: +86 1088196959, Fax: +86 1088196064, e-mail: niru7429@126.com

Key Words: Renal cell carcinoma, vascular endothelial growth inhibitor (VEGI), epithelial-mesenchymal transition. tumor metastasis through inhibiting EMT in RCC in vivo. This may provide a new approach for the treatment of RCC.

Renal cell carcinoma (RCC) is the most common malignancy of the kidney (1). It generally arises from the renal epithelium and accounts for $\sim 85 \%$ of all renal malignancies (2). In the United States, about 63,990 cases of kidney cancer are expected to occur and lead to more than 14,400 deaths in 2017 (3). One-third of patients present with locally advanced or metastatic disease, and $\sim 20-40 \%$ of those who undergo surgical resection of the primary tumor will develop metastatic disease (4). Metastatic RCC has a poor prognosis, with a median overall survival of 12 months and a 5-year survival rate of less than $10 \%$, which seriously affects patients' quality of life (5).

Over the past decade, significant progress has been made in the development of targeted therapies for patients with advanced RCC (6). The majority of these targeted therapies directly or indirectly inhibit the vascular endothelial cell growth factor (VEGF) pathway. RCC appears to be a tumor uniquely sensitive to strategies that target and inhibit tumorassociated angiogenesis. However, despite the advent of these agents, such as sunitinib, sorafenib, temsirolimus, bevacizumab and axitinib, the benefits are limited and many patients with advanced RCC experience progression during therapy and eventually die of their disease. It has become clear that RCC is not a single disease but exhibits a variety of different clinical courses, responding differently to targeted therapies. Therefore, new strategies or targets are needed for the treatment of these patients.

Vascular endothelial growth inhibitor (VEGI), a member of the tumor necrosis factor superfamily, has been identified as an anti-angiogenic cytokine $(7,8)$. The gene (Gene ID: 
Table I. Characteristics of the antibodies used in the study.

\begin{tabular}{|c|c|c|c|c|}
\hline Antibody & Catalog number & Description & Dilution & Manufacturer \\
\hline E-Cadherin & ab76319 & Rabbit monoclonal & $1: 100$ & Abcam, UK \\
\hline Vimentin & ab92547 & Rabbit monoclonal & $1: 250$ & Abcam, UK \\
\hline $\mathrm{N}$-Cadherin & ab18203 & Rabbit polyclonal & $1: 500$ & Abcam, UK \\
\hline Vascular endothelial cell growth factor & ab53465 & Rabbit polyclonal & $1: 500$ & Abcam, UK \\
\hline Secondary antibody & PV-9001 & HRP Anti-Rabbit IgG & - & $\begin{array}{c}\text { Zhongshan Golden Bridge Biotech } \\
\text { Company (Beijing, China) }\end{array}$ \\
\hline
\end{tabular}

9966) encoding it is located on human chromosome $9 \mathrm{q} 32$. The full-length of VEGI gene is $\sim 17 \mathrm{~kb}$, which consists of four exons and three introns. Three alternatively spliced isoforms of VEGI, VEGI174, -192, and -251 have been documented, sharing 151 common C-terminal amino acids but differing in their $N$-terminal regions. The initially reported VEGI protein consists of 174 amino acids which can be divided into two parts: the 1-25 amino acid residues at the $N$-terminus are intracellular and transmembrane domain; and the 26-174 amino acid residues at the $C$ terminus form an extracellular domain $(9,10)$. Expression of VEGI has been found in kidney, bladder, prostate, lung, breast and colon tissues (11-18). Our previous studies showed that VEGI overexpression significantly reduced cellular motility and adhesion of prostate and bladder cancer cells and suppressed renal cell carcinoma growth in vivo (1419). The results revealed that VEGI has inhibitory effects on tumors and it is meaningful to further study its biological functions in tumors.

In the present study, protein VEGI174 was synthesized. The effect of VEGI174 on tumor growth and epithelialmesenchymal transition (EMT) was evaluated in vivo. EMT is a key event in tumor invasion and metastasis. Uncovering the relationship between VEGI174 and EMT will provide a more comprehensive understanding of the biological function of VEGI174.

\section{Materials and Methods}

Biosynthesis of VEGI174 protein. VEGI174 protein was biosynthesized by WuHan Moon Biosciences Limited Company (WuHan, China). The amino acid sequence of VEGI174 protein is MRRFLSKVYS FPMRKLILFL VFPVVRQTPT QHFKNQFPAL HWEHELGLAF TKNRMNYTNK FLLIPESGDY FIYSQVTFRG MTSECSEIRQ AGRPNKPDSI TVVITKVTDS YPEPTQLLMG TKSVCEVGSN WFQPIYLGAM FSLQEGDKLM VNVSDISLVD YTKEDKTFFG AFLL (GenBank: AAD08783.1). The test sample was qualified by WuHan Moon Biosciences Limited Company.

Cell line and culture. RCC cell line A498 was provided by Sun YatSen University Laboratory (Guangzhou, China). A498 cells were cultured in Eagle's minimum essential medium (Hyclone, Thermo
Fisher Scientific Inc., Waltham, MA, USA), containing 10\% fetal bovine serum (FBS; Gibco Life Technologies, Grand Island, NY, USA), $100 \mathrm{unit} / \mathrm{ml}$ penicillin, and $100 \mu \mathrm{g} / \mathrm{ml}$ streptomycin (Hyclone, Thermo Fisher Scientific Inc.). Cultures were maintained at $37^{\circ} \mathrm{C}$ in a humidified atmosphere of $95 \%$ air and $5 \% \mathrm{CO}_{2}$.

Animals and ethics statement. All female BALB/c nude mice (4-6 weeks, 16-20 g) were supplied by Beijing FuKang Bioscience Limited company (SPF, Beijing, China; Animal Certificate No.: 11401300025891). All procedures related to animal handling, care, and treatment in this study were performed according to the guidelines approved by the Institutional Animal Care and Use Committee of Crown Bioscience following the guidance of the Association for Assessment and Accreditation of Laboratory Animal Care.

Animal experiments. Ten BALB/C nude mice were randomly divided into two groups: Group 1: Saline-treated control group, and group 2: VEGI174-treated group. In the tumor xenograft experiment, $3 \times 10^{6} \mathrm{~A} 498$ cells were subcutaneously injected into the right lateral axilla of the nude mice. The administration of saline (50 $\mu \mathrm{l} /$ mouse) or VEGI174 ( $5 \mathrm{mg} / \mathrm{kg}, 50 \mu \mathrm{l} /$ mouse) injection was initiated in mice when the tumor size reached $200 \mathrm{~mm}^{3}$. Treatments were injected into the tumors every 2 days. The diameters of developing tumors were evaluated twice each week. Tumor volumes were calculated according to the following equation: tumor volume $\left(\mathrm{mm}^{3}\right)=\left(\right.$ length $\times$ width $\left.{ }^{2}\right) / 2$, where length and width were measured as the maximum and the minimum tumor diameters, respectively (20). At the end of the experiment, the animals were sacrificed with cervical dislocation, and the tumor specimens were harvested.

Immunohistochemical staining. Immunohistochemical assay was performed on tumor tissues in accordance with a standard immunostaining protocol. Paraffin sections were deparaffinized in xylene, washed in decreasing alcohol concentrations, and rehydrated in deionized water. Antigen retrieval was performed in $0.1 \mathrm{M}$ citrate buffer for $10 \mathrm{~min}$ at $98^{\circ} \mathrm{C}$. Endogenous peroxidase activity was blocked by immersing the slides in $3 \%$ hydrogen peroxide for $10 \mathrm{~min}$. The slides were incubated at $4^{\circ} \mathrm{C}$ overnight with different primary antibodies at assay-dependent concentration. The characteristics of the antibodies used in the study are listed in Table I. The slides were then incubated with polyperoxidase-antimouse/rabbit IgG. Peroxidase reaction was performed using 3,3'diaminobenzidine (DAB; Zhongshan Gloden Bridge Biotech Company, Beijing, China). Finally, the slides were counterstained with hematoxylin, dehydrated using the aforementioned alcohol 


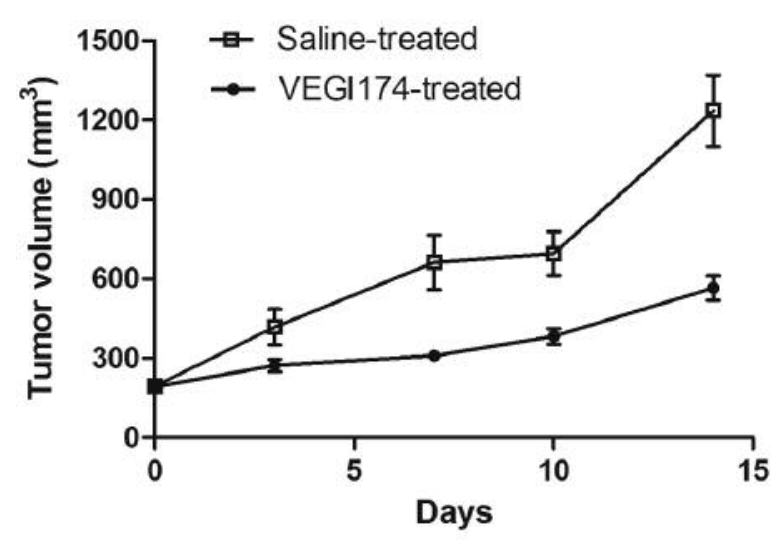

Figure 1. The tumor growth curves of saline-treated group and VEGI174-treated group. Tumor growth was much slower in the VEGI174-treated group compared with the saline-treated group.

series for $2 \mathrm{~min}$ each, cleared in two changes of xylene for $2 \mathrm{~min}$, and mounted with xylene-based mounting medium.

Evaluation of immunohistochemical staining. Evaluation of staining reaction was performed in accordance with the immunoreactive score (IRS) proposed by Remmele and Stegner (21): IRS=SI $\times$ PP, where PI is the staining intensity and PP the percentage of positively stained cells. An SI scored 0 when negative; 1, weakly stained; 2, moderately stained; and 3 , strongly stained. PP scored 0 when negative; 1 , with $10 \%$ positively stained cells; $2,11-50 \%$ positively stained cells; $3,51-80 \%$ positively stained cells; and 4 , more than $80 \%$ positively stained cells. Ten visual fields from different areas of each tumor were used for the IRS evaluation.

Statistical analysis. All of the statistical analysis was performed with SPSS 19.0 software (IBM Corp., Armonk, NY, USA). The measurement data are reported as the mean \pm standard deviation. Comparisons among IRS data sets were made with paired $t$-test. Differences were considered to be statistically significant when the $p$-value was less than 0.05 .

\section{Results}

VEGI174 inhibited RCC cell growth in vivo. The A498 implantation tumor rate in nude mice was $100 \%$, and then the nude mice were randomly selected and treated with saline or VEGI174 every 2 days by intra-tumoral injection. The mean A498 tumor volume at baseline was similar in the two groups. VEGI174 treatment significantly reduced the tumor growth, as shown by tumor size compared with the saline control (Figure 1).

Expression of EMT markers and VEGF. The expression of E-cadherin protein was primarily localized on the cell membrane. Compared with the saline-treated tumor tissues, the IRS of the VEGI174-treated group was significantly

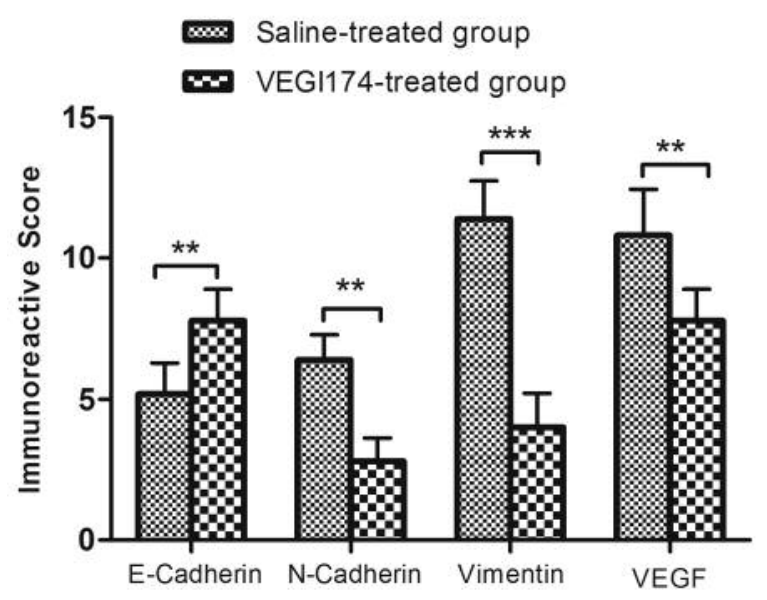

Figure 2. Immunoreactive scores for epithelial-mesenchymal transition markers (E-cadherin, N-cadherin and vimentin) and vascular endothelial cell growth factor (VEGF). Compared to the saline-treated group, the expression of E-cadherin was significantly higher in the VEGI174-treated group. However, the expression of $N$-cadherin and vimentin was reduced in VEGI174-treated tumor tissues. The expression of VEGF was significantly lower in the VEGI174-treated group compared to the saline-treated group. Significantly different at $* * p<0.01$ and $* * * p<0.001$.

higher ( $p<0.01$, Figure 2). Compared with the saline-treated tumor tissues, E-cadherin positivity was significantly higher in VEGI174 treated tissues (Figure 3A). The expression of $\mathrm{N}$-cadherin was detected in the cytoplasm. The IRS for $\mathrm{N}$ cadherin for the VEGI174-treated group was significantly lower than that of the saline-treated group $(p<0.01$, Figure 2 ). The $\mathrm{N}$-cadherin-positive rate in the saline-treated tumor tissues was higher than in the VEGI174-treated tissues (Figure 3B). Vimentin was also located in the cytoplasm. The IRS for vimentin for the VEGI174-treated group was significantly lower than that of the saline-treated group $(p<0.001$, Figure 2). The expression of vimentin was higher in the saline-treated tumor tissues compared with the VEGI174-treated tissues (Figure 3C). The expression of VEGF was distributed in the cytoplasm and extracellular matrix. The IRS for VEGF for the VEGI174-treated group was significantly lower than that of the saline-treated group $(p<0.01$, Figure 2). Compared with the saline-treated group, the expression of VEGF was significantly decreased in VEGI174-treated tumor tissues (Figure 3D).

\section{Discussion}

VEGI174 is a cytokine that belongs to the TNF ligand family. The protein is abundantly expressed in endothelial cells. This cytokine is a ligand for receptor TNFRSF25 and decoy receptor 3 (DR3) (22). It can activate nuclear factor- 
Saline-treated group

A

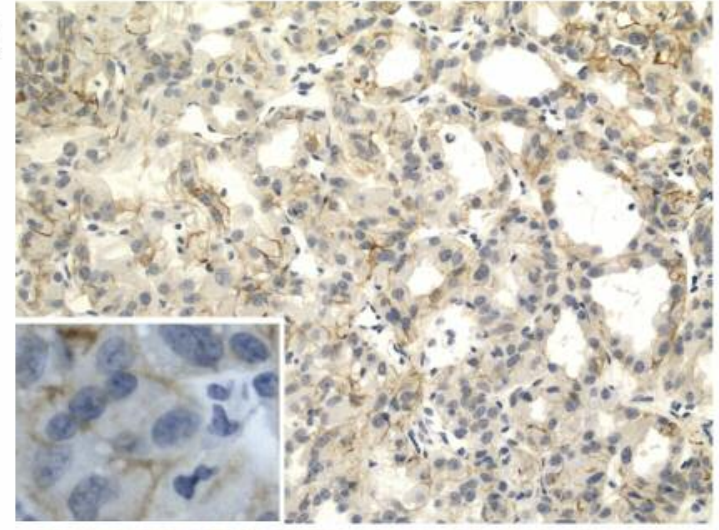

B

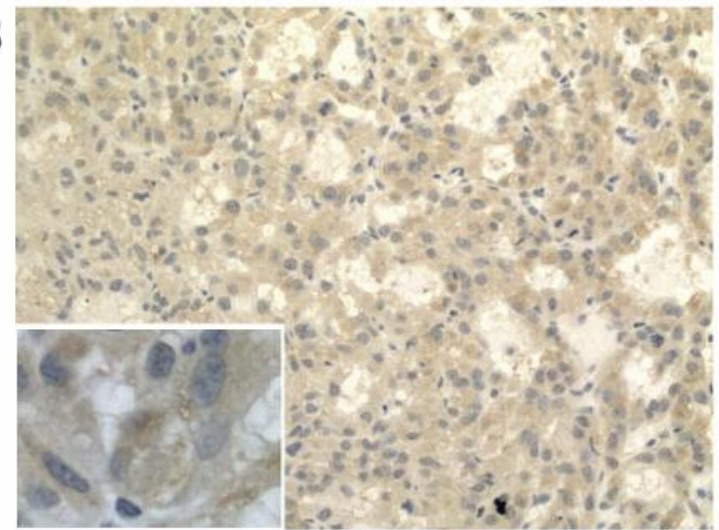

C

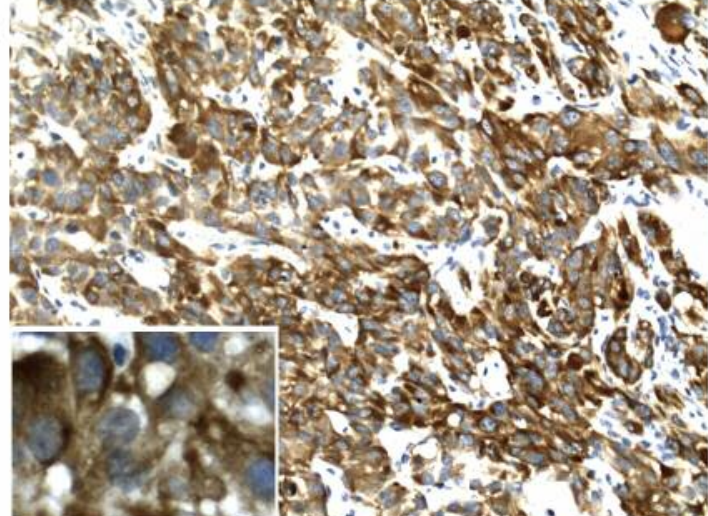

D

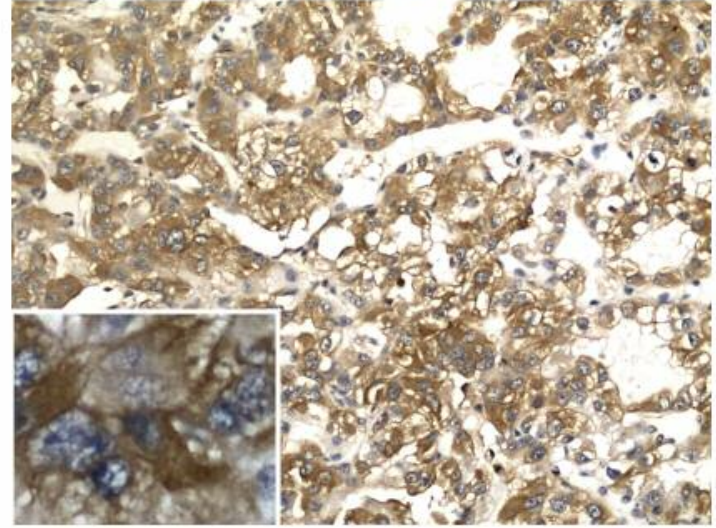

VEGI174-treated group

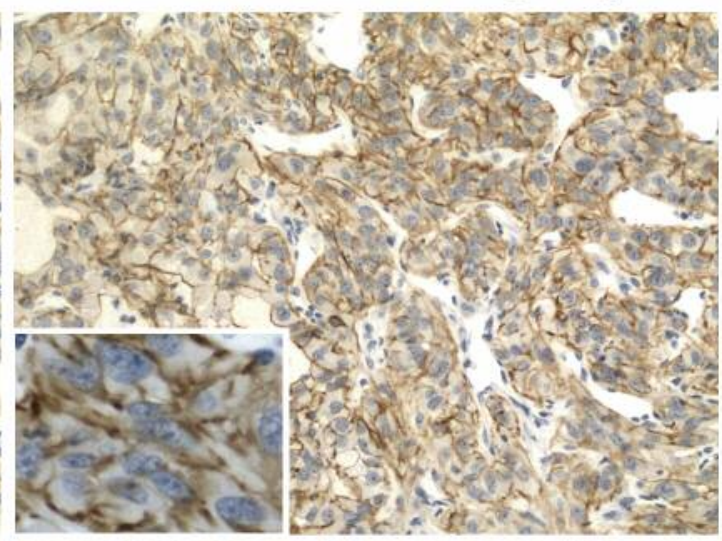

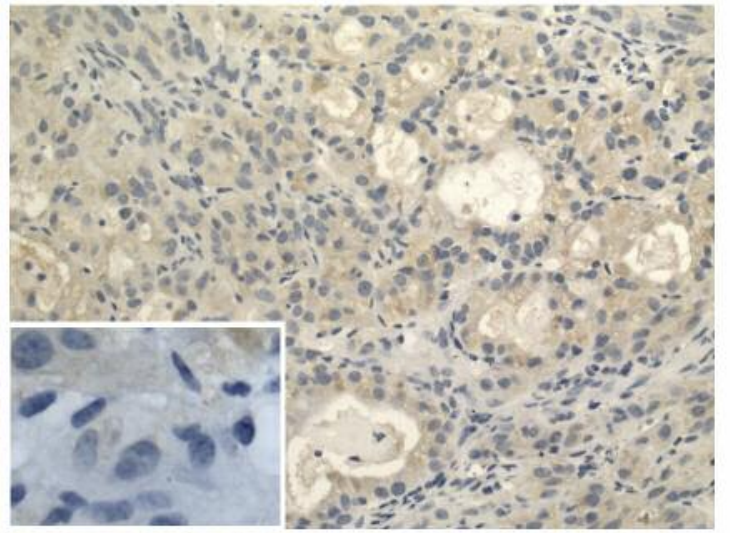

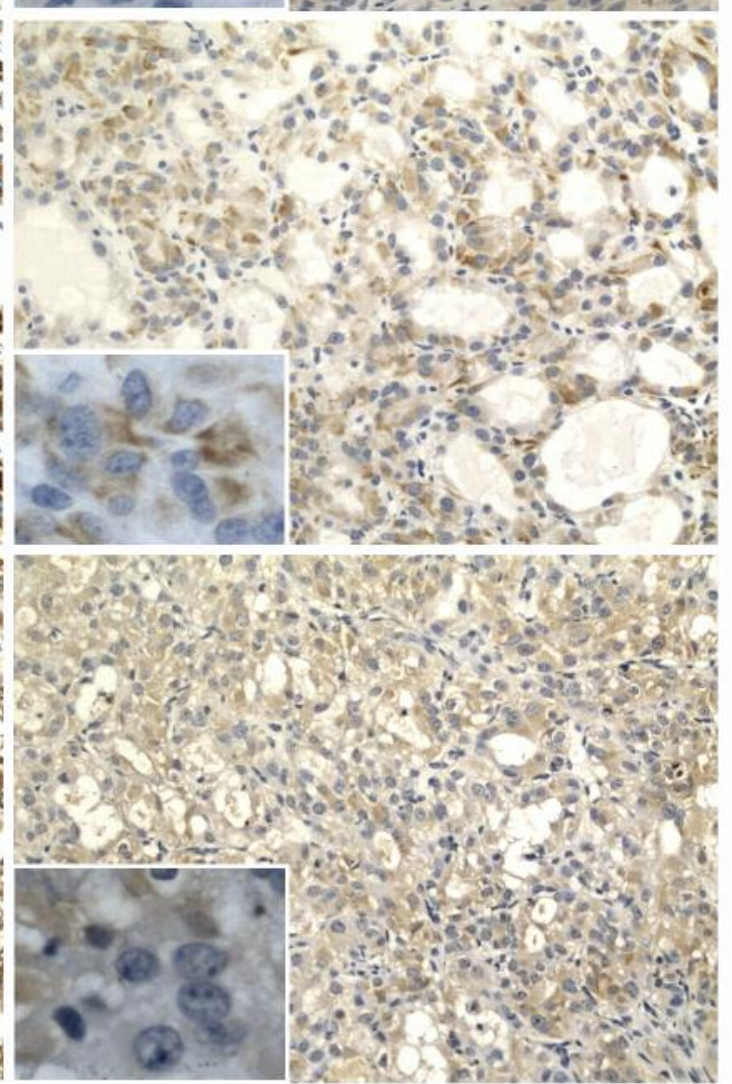


kappa-binding (NF-kB) and mitogen-activated protein kinase (MAPK), and acts as an autocrine factor to induce apoptosis in endothelial cells (11). The cytokine also inhibits endothelial cell proliferation, and thus may function as an angiogenic inhibitor (23). Multiple studies have investigated the expression and bio-functions of VEGI in cancer. Parr et al. reported that VEGI is aberrantly expressed in breast cancer and has a prognostic relevance. Patients with breast tumors expressing reduced levels of VEGI had a poorer prognosis than patients expressing high levels of VEGI (13). Chew et al. reported that overexpression of VEGI abrogated xenograft tumor progression by reducing the tumor growth rate and microvessel density (9). VEGI was also found to regulate the biofunctions of many tumor cell lines: such as breast carcinoma (MCF-7), epithelial (HeLa) and myeloid (U-937 and ML-1a) tumor cells $(24,25)$. Furthermore, our previous studies demonstrated that overexpression of VEGI inhibited in vitro cell motility, vascular endothelial tube formation and tumor growth in vivo (14-18).

In this study, we detected the biological effects of VEGI174 protein on tumors implanted in mice. The tumor growth curves showed that tumor growth in the VEGI174-treated group was slower than that of the saline-treated group. This result was consistent with VEGI174 gene overexpression experiments in RCC cell lines (16). The expression level of VEGF that was detected by IHC was significantly decreased in the VEGI174-treated group compared to the saline-treated group. Zhang et al. reported that VEGF gene expression could be suppressed by TNFSF15 (VEGI)-stimulated activation of the Jun $N$-terminal kinase-GATA binding protein 3 (JNKGATA3) signaling pathway (26). Qi et al. found that VEGI inhibited vasculogenesis by regulating relative levels of membrane-bound and soluble isoforms of VEGF receptor 1 (23). Therefore, this suggested that VEGI174 protein inhibition of tumor growth may depend on negatively regulating the expression of VEGF.

Furthermore, we investigated the effect of VEGI174 protein on epithelial-mesenchymal transition (EMT). In recent years, numerous studies demonstrated that activation

Figure 3. The expression of epithelial-mesenchymal transition markers (E-cadherin, $N$-cadherin and vimentin) and vascular endothelial cell growth factor (VEGF) in the saline-treated group and VEGI174-treated group. A: The expression of E-cadherin (yellow staining) was lower in the saline-treated group than in the VEGI174-treated group. B: The expression of $\mathrm{N}$-cadherin (yellow staining) was higher in the saline-treated group than in the VEGI174-treated group. C: The expression of vimentin (brown staining) was higher in the saline-treated group than VEGI174-treated group. D: The expression of VEGF (yellow brown staining) was higher in the saline-treated group than VEGI174-treated group. (Original magnification: $\times 200$, insets: $\times 400$ ). of EMT is a key event in the tumor invasion process (27-29). EMT is a biological phenomenon which frequently occurs in tumor tissues and is associated with local invasion and distant metastasis. It has been studied in multiple cancer types such as those of the digestive tract, pancreas, liver, prostate and breast (30-36). Zhang et al. demonstrated that EMT enhanced the invasion and migration of HCC cells (37). Chu et al. showed that EMT was closely related to cell migration and invasion in breast cancer (38). Therefore, further study is essential to investigate the relationships between VEGI174 and EMT. It will help to provide insights into the biofunctions of VEGI174 and may provide a potential therapy for RCC.

There was a significant difference in the expression levels of EMT markers between the saline-treated and VEGI174treated groups. Compared with the saline-treated group, the expression level of E-cadherin was significantly higher in the VEGI174-treated group. However, the expression levels of $\mathrm{N}$-cadherin and vimentin were decreased in VEGI174-treated tumor tissues. E-Cadherin is an intercellular adhesion molecule that enhances the connections between cells and maintains the stability of the cytoskeleton. Many signaling pathways promote EMT by suppressing expression of Ecadherin $(39,40)$. N-Cadherin, a well-known EMT marker, acts as a major oncogene in diverse cancer types. A universal hallmark of the EMT phenotype is the loss-of-function of Ecadherin and gain-of-function of $\mathrm{N}$-cadherin in tumorigenesis $(41,42)$. Vimentin is overexpressed in malignant epithelial cancers and correlates with poor prognosis. Abundant evidence indicates that vimentin regulates mesenchymal cell shape and mammary epithelial cell migration, and plays a role in regulating signal transduction, necessary for EMT induction (43-45). According to our results, the mesenchymal markers were down-regulated, while the epithelial marker was up-regulated in the VEGI174-treated group. This demonstrated that VEGI174 inhibited EMT in vivo.

In conclusion, our study showed that VEGI174 protein not only inhibited tumor growth but also regulated the process of EMT in implantation of RCC tumors. It also suggests that VEGI174 may play a crucial role against RCC development and metastasis. It also may provide a new approach for the treatment of RCC. In subsequent studies, more biological functions of VEGI174 in RCC and the mechanisms of molecular regulation should be carefully elucidated.

\section{Conflicts of Interest}

The Authors report no conflicts of interest.

\section{Acknowledgements}

This study was supported by the National Natural Science Foundation of China, grant No. 81372138 and Cancer Research Wales (W.G.J.). 


\section{References}

1 Nguyen MM, Gill IS and Ellison LM: The evolving presentation of renal carcinoma in the United States: trends from the Surveillance, Epidemiology, and End Results program. J Urol 176: 2397-2400, 2006.

2 Cohen HT and McGovern FJ: Renal-cell carcinoma. N Engl J Med 353: 2477-2490, 2005.

3 The State of Cancer Care in America, 2017: A Report by the American Society of Clinical Oncology. J Oncol Pract 13: e353e394, 2017.

4 Russo P: Renal cell carcinoma: presentation, staging, and surgical treatment. Semin Oncol 27: 160-176, 2000.

5 Liu L, Zhang W, Qi X, Li H, Yu J, Wei S, Hao X and Ren X: Randomized study of autologous cytokine-induced killer cell immunotherapy in metastatic renal carcinoma. Clin Cancer Res 18: 1751-1759, 2012.

6 Jonasch E and Motzer RJ: Ten years of progress in renal cell carcinoma. J Natl Compr Canc Netw 10: 690-693, 2012.

7 Tan KB, Harrop J, Reddy M, Young P, Terrett J, Emery J, Moore $\mathrm{G}$ and Truneh A: Characterization of a novel TNF-like ligand and recently described TNF ligand and TNF receptor superfamily genes and their constitutive and inducible expression in hematopoietic and non-hematopoietic cells. Gene 204: 35-46, 1997.

8 Zhai Y, Yu J, Iruela-Arispe L, Huang WQ, Wang Z, Hayes AJ, Lu J, Jiang G, Rojas L, Lippman ME, Ni J, Yu GL and Li LY: Inhibition of angiogenesis and breast cancer xenograft tumor growth by VEGI, a novel cytokine of the TNF superfamily. Int J Cancer 82: 131-136, 1999.

9 Chew LJ, Pan H, Yu J, Tian S, Huang WQ, Zhang JY, Pang S and Li LY: A novel secreted splice variant of vascular endothelial cell growth inhibitor. FASEB J 16: 742-744, 2002.

10 Zhang N, Sanders AJ, Ye L and Jiang WG: Vascular endothelial growth inhibitor in human cancer (Review). Int J Mol Med 24: 3-8, 2009.

11 Zhai Y, Ni J, Jiang GW, Lu J, Xing L, Lincoln C, Carter KC, Janat F, Kozak D, Xu S, Rojas L, Aggarwal BB, Ruben S, Li LY, Gentz R and Yu GL: VEGI, a novel cytokine of the tumor necrosis factor family, is an angiogenesis inhibitor that suppresses the growth of colon carcinomas . FASEB J 13: 181$189,1999$.

12 Liang PH, Tian F, Lu Y, Duan B, Stolz DB and Li LY: Vascular endothelial growth inhibitor (VEGI; TNFSF15) inhibits bone marrow-derived endothelial progenitor cell incorporation into Lewis lung carcinoma tumors. Angiogenesis 14: 61-68, 2011.

13 Parr $\mathrm{C}$, Gan $\mathrm{CH}$, Watkins $\mathrm{G}$ and Jiang WG: Reduced vascular endothelial growth inhibitor (VEGI) expression is associated with poor prognosis in breast cancer patients. Angiogenesis 9: 73-81, 2006.

14 Zhang N, Sanders AJ, Ye L, Kynaston HG and Jiang WG: Vascular endothelial growth inhibitor, expression in human prostate cancer tissue and the impact on adhesion and migration of prostate cancer cells in vitro. Int J Oncol 35: 1473-1480, 2009.

15 Zhang N, Sanders AJ, Ye L, Kynaston HG and Jiang WG: Expression of vascular endothelial growth inhibitor (VEGI) in human urothelial cancer of the bladder and its effects on the adhesion and migration of bladder cancer cells in vitro. Anticancer Res 30: 87-95, 2010.
16 Zhang N, Wu P, Shayiremu D, Wu L, Shan H, Ye L, Zhao X, Cai J, Jiang WG, Gong K and Yang Y: Suppression of renal cell carcinoma growth in vivo by forced expression of vascular endothelial growth inhibitor. Int J Oncol 42: 16641673, 2013.

17 Wu L, Li X, Ye L, Shayiremu D, Deng X, Zhang X, Jiang W, Yang Y, Gong K and Zhang N: Vascular endothelial growth inhibitor 174 is a negative regulator of aggressiveness and microvascular density in human clear cell renal cell carcinoma. Anticancer Res 34: 715-722, 2014.

18 Wu LY, Cheng H, Deng XH, Shan H, Wang W, Yang Y, Zhang $\mathrm{XD}$ and Zhang N: Expression and role of vascular endothelial growth inhibitor in sporadic clear cell renal cell carcinoma. Zhonghua Yi Xue Za Zhi 93: 741-745, 2013 (in Chinese).

19 Zhang N, Wu P, Wu L, Shayiremu D, Shan H, Ye L, Jiang WG, Gong $\mathrm{K}$ and Yang Y: The differential expression of vascular endothelial growth inhibitor isoforms, VEGI251, VEGI174 and VEGI192 in human clear-cell renal cell carcinoma. Cancer Genomics Proteomics 10: 47-53, 2013.

20 Martinelli E, Troiani T, D'Aiuto E, Morgillo F, Vitagliano D, Capasso A, Costantino S, Ciuffreda LP, Merolla F, Vecchione L, De Vriendt V, Tejpar S, Nappi A, Sforza V, Martini G, Berrino L, De Palma R and Ciardiello F: Antitumor activity of pimasertib, a selective MEK $1 / 2$ inhibitor, in combination with $\mathrm{PI} 3 \mathrm{~K} / \mathrm{mTOR}$ inhibitors or with multi-targeted kinase inhibitors in pimasertib-resistant human lung and colorectal cancer cells. Int J Cancer 133: 2089-2101, 2013.

21 Remmele W and Stegner HE: Recommendation for uniform definition of an immunoreactive score (IRS) for immunohistochemical estrogen receptor detection (ER-ICA) in breast cancer tissue. Pathologe 8: 138-140, 1987 (in German).

$22 \mathrm{Ge}$ Z, Sanders AJ, Ye L, Mansel RE and Jiang WG: Expression of death receptor-3 in human breast cancer and its functional effects on breast cancer cells in vitro. Oncol Rep 29: 1356-1364, 2013.

23 Qi JW, Qin TT, Xu LX, Zhang K, Yang GL, Li J, Xiao HY, Zhang ZS and Li LY: TNFSF15 inhibits vasculogenesis by regulating relative levels of membrane-bound and soluble isoforms of VEGF receptor 1. Proc Natl Acad Sci USA 110: 13863-13868, 2013.

24 Xiao Q, Hsu CY, Chen H, Ma X, Xu J and Lee JM: Characterization of cis-regulatory elements of the vascular endothelial growth inhibitor gene promoter. Biochem J 388: 913920, 2005.

25 Haridas V, Shrivastava A, Su J, Yu GL, Ni J, Liu D, Chen SF, Ni Y, Ruben SM, Gentz R and Aggarwal BB: VEGI, a new member of the TNF family activates nuclear factor-kappa B and c-Jun N-terminal kinase and modulates cell growth. Oncogene 18: 6496-6504, 1999.

26 Zhang K, Cai HX, Gao S, Yang GL, Deng HT, Xu GC, Han J, Zhang QZ and Li LY: TNFSF15 suppresses VEGF production in endothelial cells by stimulating miR-29b expression via activation of JNK-GATA3 signals. Oncotarget 7: 69436-69449, 2016.

27 De Craene B and Berx G: Regulatory networks defining EMT during cancer initiation and progression. Nat Rev Cancer 13: 97110, 2013.

28 Thiery JP, Acloque H, Huang RY and Nieto MA: Epithelialmesenchymal transitions in development and disease. Cell 139: 871-890, 2009. 
29 Wong IY, Javaid S, Wong EA, Perk S, Haber DA, Toner M and Irimia D: Collective and individual migration following the epithelial-mesenchymal transition. Nat Mater 13: 1063-1071, 2014

30 Ho QT and Kuo CJ: Vascular endothelial growth factor: biology and therapeutic applications. Int J Biochem Cell Biol 39: 13491357, 2007.

31 Byles V, Zhu L, Lovaas JD, Chmilewski LK, Wang J, Faller DV and Dai Y: SIRT1 induces EMT by cooperating with EMT transcription factors and enhances prostate cancer cell migration and metastasis. Oncogene 31: 4619-4629, 2012.

32 Chen J, Imanaka N, Chen J and Griffin JD: Hypoxia potentiates Notch signaling in breast cancer leading to decreased E-cadherin expression and increased cell migration and invasion. $\mathrm{Br} \mathrm{J}$ Cancer 102: 351-360, 2010.

33 Sato F, Kubota Y, Natsuizaka M, Maehara O, Hatanaka Y, Marukawa K, Terashita K, Suda G, Ohnishi S, Shimizu Y, Komatsu Y, Ohashi S, Kagawa S, Kinugasa H, Whelan KA Nakagawa $\mathrm{H}$ and Sakamoto N: EGFR inhibitors prevent induction of cancer stem-like cells in esophageal squamous cell carcinoma by suppressing epithelial-mesenchymal transition Cancer Biol Ther 16: 933-940, 2015.

34 Jiao L, Li DD, Yang CL, Peng RQ, Guo YQ, Zhang XS and Zhu XF: Reactive oxygen species mediate oxaliplatin-induced epithelial-mesenchymal transition and invasive potential in colon cancer. Tumour Biol 37: 8413-8423, 2016.

35 Liang B, Zheng W, Fang L, Wu L, Zhou F, Yin X, Yu X and Zou $\mathrm{Z}$ : Overexpressed targeting protein for Xklp2 (TPX2) serves as a promising prognostic marker and therapeutic target for gastric cancer. Cancer Biol Ther 17: 824-832, 2016.

36 Krantz SB, Shields MA, Dangi-Garimella S, Munshi HG and Bentrem DJ: Contribution of epithelial-to-mesenchymal transition and cancer stem cells to pancreatic cancer progression. J Surg Res 173: 105-112, 2012.

37 Zhang L, Huang G, Li X, Zhang Y, Jiang Y, Shen J, Liu J, Wang Q, Zhu J, Feng X, Dong J and Qian C: Hypoxia induces epithelial-mesenchymal transition via activation of SNAI1 by hypoxia-inducible factor-1alpha in hepatocellular carcinoma BMC Cancer 13: 108, 2013.
38 Chu CY, Jin YT, Zhang W, Yu J, Yang HP, Wang HY, Zhang ZJ, Liu XP and Zou Q: CA IX is upregulated in $\mathrm{CoCl} 2$-induced hypoxia and associated with cell invasive potential and a poor prognosis of breast cancer. Int J Oncol 48: 271-280, 2016.

39 Lombaerts M, Middeldorp JW, van der Weide E, Philippo K, van Wezel T, Smit VT, Cornelisse CJ and Cleton-Jansen AM: Infiltrating leukocytes confound the detection of E-cadherin promoter methylation in tumors. Biochem Biophys Res Commun 319: 697-704, 2004.

40 Natalwala A, Spychal R and Tselepis C: Epithelial-mesenchymal transition mediated tumourigenesis in the gastrointestinal tract. World J Gastroenterol 14: 3792-3797, 2008.

41 Larue L and Bellacosa A: Epithelial-mesenchymal transition in development and cancer: role of phosphatidylinositol 3' kinase/AKT pathways. Oncogene 24: 7443-7454, 2005.

42 Nieman MT, Prudoff RS, Johnson KR and Wheelock MJ: Ncadherin promotes motility in human breast cancer cells regardless of their E-cadherin expression. J Cell Biol 147: 631-644, 1999.

43 Gilles C, Polette M, Zahm JM, Tournier JM, Volders L, Foidart $\mathrm{JM}$ and Birembaut P: Vimentin contributes to human mammary epithelial cell migration. J Cell Sci 112(Pt 24): 4615-4625, 1999.

44 Mendez MG, Kojima S and Goldman RD: Vimentin induces changes in cell shape, motility, and adhesion during the epithelial to mesenchymal transition. FASEB J 24: 1838-1851, 2010.

45 Vuoriluoto K, Haugen H, Kiviluoto S, Mpindi JP, Nevo J, Gjerdrum C, Tiron C, Lorens JB and Ivaska J: Vimentin regulates EMT induction by SLUG and oncogenic H-RAS and migration by governing AXL expression in breast cancer. Oncogene 30: 1436-1448, 2011.
Received April 6, 2017

Revised April 20, 2017

Accepted April 24, 2017 